\title{
NEUROPHYSIOLOGICAL MEASURES OF AUDITORY SENSORY PROCESSING ARE ASSOCIATED WITH ADAPTIVE BEHAVIOR IN CHILDREN WITH AUTISM SPECTRUM DISORDER
}

\author{
Mairin Cotter ${ }^{1,2}$, Seydanur Tikir ${ }^{1,3,4}$, Ana Alves Francisco ${ }^{1,3,5}$, Leona Oakes ${ }^{1,4}$, Michael J. \\ Crosse $^{6,7}$, John J. Foxe ${ }^{1,3,4}$, Sophie Molholm*1,3,4,5 \\ 1) The Cognitive Neurophysiology Laboratory, Department of Pediatrics, \\ Albert Einstein College of Medicine, Bronx, New York 10461, USA \\ 2) Department of Psychology, Fordham University, Bronx, New York, 10458, USA \\ 3) Department of Neuroscience, Albert Einstein College of Medicine, \\ Bronx, New York 10461, USA \\ 4) The Frederick J. and Marion A. Schindler Cognitive Neurophysiology Laboratory, The Ernest J. Del Monte \\ Institute for Neuroscience, Department of Neuroscience, University of \\ Rochester School of Medicine and Dentistry, Rochester, New York 14642, USA \\ 5) Department of Psychiatry and Behavioral Sciences, Albert Einstein \\ College of Medicine, Bronx, New York 10461, USA \\ 6) Segotia, Galway, Ireland \\ 7) Trinity Centre for Biomedical Engineering, Trinity College Dublin, Dublin, Ireland \\ *Corresponding Author
}




\begin{abstract}
Background: Atypical auditory cortical processing is consistently found in scalp electrophysiological and magnetoencephalographic studies of Autism Spectrum Disorder (ASD), and may provide a marker of neuropathological brain development. However, the relationship between atypical cortical processing of auditory information and adaptive behavior in ASD is not yet well understood.

Methods: We sought to test the hypothesis that early auditory processing in ASD is related to everyday adaptive behavior through the examination of auditory event-related potentials (AEPs) in response to simple tones and Vineland Adaptive Behavior Scales in a large cohort of children with ASD (N=89), aged 6-17, and in age- and IQ- matched neurotypically (NT) developing controls ( $\mathrm{N}=120)$.

Results: Statistical analyses revealed significant group differences in early AEPs over temporal scalp regions. Whereas the expected rightward lateralization of the AEP to tonal stimuli occurred in both groups, lateralization of the AEP was only significantly associated with adaptive functioning, in the domains of communication and daily living, in the ASD group.

Conclusions: These results lend support to the hypothesis that atypical processing of sensory information is related to everyday adaptive behavior in autism.
\end{abstract}

Keywords: Autism Spectrum Disorder, electroencephalography, adaptive behavior, event related potentials, lateralization, auditory processing 


\section{Background}

Cortical sensory processing differences in Autism Spectrum Disorder (ASD) may be indicative of aberrant neurodevelopment, and are likely to have cascading effects on higher order cognitive processes (Lewis et al., 2017) that in turn impact clinical phenotype. Studies using electrophysiological (EEG) recordings to examine the brain response to auditory stimulation in ASD consistently reveal smaller and/or slightly delayed auditory evoked potentials (AEP for EEG recordings; auditory evoked magnetic fields (AEMF) for magnetoencephalographic (MEG) recordings) 100-200 ms post stimulus onset over frontal and lateral temporal scalp regions in comparison to age-matched neurotypical (NT) controls (Brandwein et al., 2013; Bruneau et al., 2003; Jansson-Verkasalo et al., 2003; Orekhova et al., 2009; Stroganova et al., 2013). As such AEPs present a strong candidate for a neural marker of cognitive, clinical, and behavioral sequelae of ASD.

Prior work has been directed at exploring relationships between atypical AEPs and the autism phenotype (Brandwein et al., 2015; Foss-Feig et al., 2018), yet very few studies have focused on the relationship between cortical auditory sensory processing and how well a child with a diagnosis of ASD is able to navigate age-appropriate everyday situations ("adaptive behavior"). The Vineland Adaptive Behavior Scales (Vineland) provide an age appropriate measurement of adaptive behavior in the areas of socialization, communication, daily living, motor skills, and maladaptive behavior (Sparrow et al., 2005), and can be used to represent the impact of a neurodevelopmental condition on daily living (Carter et al., 1998). Focusing on the communication domain, Roberts and colleagues (Matsuzaki, Ku, et al., 2019; Roberts et al., 2019) found that the latency of the early auditory MEG response to tonal stimuli was correlated with Vineland adaptive communication scores in a sample of ASD and NT children. Here, we sought to further explore the relationship between auditory processing in ASD and adaptive behavior, by evaluating the relationship between the Vineland domains of socialization and daily living skills in addition to the domain of communication in a large sample of children and adolescents with ASD, using high-density EEG to index auditory sensory processing.

Brain activity in response to tonal and musical stimuli is typically stronger in the right compared to the left cortical hemisphere (E. Orekhova et al., 2013; Parviainen et al., 2019; Yamazaki et al., 2018)) (Matsuzaki, Ku, et al., 2019; Roberts et al., 2019), whereas this pattern is reversed in response to speech and language stimuli (Hornickel et al., 2009; Koyama et al., 2000; Narain et al., 2003). Lateralization of cortical function is observed in many functional domains in humans (Güntürkün et al., 2020; Samara \& Tsangaris, 2011) (Dubois et al., 2009; Habas et al., 2012) (Fair et al., 2007), and is often reduced or altered in neurodevelopmental and neuropsychiatric conditions (Berretz et al., 2020; Bishop, 2013; De Guibert et al., 2011; Groen et al., 2008; Qi et al., 2019; Ribolsi et al., 2009; Wexler, 1980). Furthermore, differences in cortical network asymmetries are seen in infants at risk for ASD (Rolison et al., 2021) as well as in sensory processing regions in infants that later go on to receive a diagnosis of ASD (Lewis et al., 2017), and there is extensive evidence for reduced lateralization of language/speech processing in ASD (Floris et al., 2020; Lindell \& Hudry, 2013). Studies similarly suggest diminished rightward lateralization for non-speech stimuli in ASD, although to date this has not been extensively reported on (Edgar et al., 2015; Gage et al., 2003; Jorgensen et al., 2021; Matsuzaki, Kuschner, et al., 2019; E. Orekhova et al., 2013; Roberts et al., 2019; Schmidt et al., 2009; Williams et al., 2020). The relationship between auditory lateralization of brain responses to tones and adaptive behavior, however, has not been previously considered. 
Here we examined AEPs to simple tones in a cohort of 89 ASD and 120 control participants, ranging in age from 6 to 17 and considered how these responses were related to adaptive behavior. We expected diminished amplitude AEPs in the ASD group compared to the NT group, as well as an atypically lateralized response. Furthermore, we expected that differences in these measures in the ASD group would be associated with poorer adaptive behavior.

\section{Participants}

\section{Methods}

The data presented here were collected at the City College of New York and the Albert Einstein College of Medicine over a 10-year period from 2008-2018. Analyses of subsets of the collected dataset have yielded several publications to date (Brandwein et al., 2013, 2015; Crosse et al., 2019; Cuppini et al., 2020). The sample consisted of children and adolescents with ASD (all were verbal) aged 6-17 and a neurotypically (NT) developing sample matched on age and performance IQ (PIQ). This yielded a sample of 114 participants with ASD (93 males, 21 females) and 142 NT participants (65 males, 77 females). After participants were excluded due to noisy EEG data, poor performance, or too few trials (detailed in Auditory ERP Analysis below), the final sample was 89 ASD participants (72 males, 17 females) and 120 NT participants (55 males, 65 females). Participants were recruited through the Human Clinical Phenotyping Core of the Rose F. Kennedy Intellectual and Developmental Disabilities Research Center, clinician referrals, advertising, and community health fairs. Exclusion criteria included a Performance IQ (PIQ) < 75, abnormal hearing or uncorrected vision, and presence of a neurological disorder. Participants in the NT group were also excluded if they had a neurodevelopmental or neuropsychiatric disorder (as assessed by extensive screening) or had a biological first degree relative with a developmental disorder. Inclusion in the clinical group required an ASD diagnosis confirmed by a trained psychologist, using the Autism Diagnostic Observation Schedule, Second Edition (ADOS-2) (Lord et al., 2012), the Autism Diagnostic Interview-Revised (ADI-R) parent interview, and clinical judgment. In studies that were conducted before 2012, the first edition of the ADOS was used. Intellectual functioning was measured by the Weschler Abbreviated Scale of Intelligence, Second Edition (WASI-II) (Wechsler, 2011). The WASI-II was not administered to 3 ASD and 1 NT participant included in the study. Participants were screened for normal hearing using audiometric threshold evaluation (below $25 \mathrm{~dB}$ HL for 500, 100, 2000, $4000 \mathrm{~Hz}$ ) performed on both ears using a Beltone Audiometer (Model 112). Before beginning the study, parents/ legal guardians gave informed written consent, and participants gave verbal or written assent. The Institutional Review Boards of the Albert Einstein College of Medicine, the City College of New York, and the Graduate Center of the City University of New York approved all procedures and were in accord with the ethical standards as stated in the Declaration of Helsinki.

\section{Clinical Measures}

Adaptive behavior was measured by the Vineland Adaptive Behavior Scale, SecondEdition parent-report questionnaire, which is an assessment tool that measures adaptive behavior for all ages in the domains of socialization, daily living, communication, motor skills, and maladaptive behavior and is an accepted measure of reported adaptive behavior in ASD (Carter et al., 1998; Perry et al., 2009; Ray-Subramanian et al., 2011; Sparrow et al., 2005). Furthermore, the Vineland is applicable to neurotypically developing children, thus allowing us to determine if adaptive behaviors are correlated with measures of auditory neural processing in both groups. In 
this study, the socialization, daily living, and communication domains were used for analysis. Motor skills and maladaptive domains were excluded because they were not age-appropriate for all participants (motor skills) and/ or are optional (maladaptive) and were not collected for most participants. We also reported the adaptive behavior composite (ABC) scores from the Vineland, which is a combined score of the socialization, daily living, and communication domains, but did not include this total score in analyses as we wished to examine the specific domains of adaptive behavior.

\section{Data Collection}

Clinical and EEG data were collected over 2 visits. In general, clinical data, including the WASI-II and ADOS, were collected during visit 1 in order to confirm an ASD diagnosis and study eligibility, and EEG recording was conducted during the second visit. During this visit, the participants performed an audiovisual simple reaction time task while continuous EEG was recorded from 70 scalp electrodes with an open pass-band from DC to $103 \mathrm{~Hz}$. There were three stimulus conditions presented in random order with equal probability (auditory alone, visual alone, and audiovisual). The "auditory alone" condition consisted of a 1000-Hz tone $75 \mathrm{dBSPL}$, $5 \mathrm{~ms}$ rise/fall time emitted from one speaker (Hartman Multimedia JBL Duet speaker) for 60ms. The visual only condition was an image of a red circle $(3.2 \mathrm{~cm}$ diameter) which was displayed on a black background $0.4 \mathrm{~cm}$ above central fixation along the vertical meridian on a computer monitor (Dell Ultrasharp 1704FTP) for $60 \mathrm{~ms}$ at a viewing distance of $122 \mathrm{~cm}$. The audiovisual condition was comprised of the auditory and visual stimuli at the same time. Stimuli were presented in blocks of 100 trials each, and participants were instructed to press a button on a response pad when they saw the instructed stimuli (circle, tone, or both circle and tone) (Brandwein et al., 2015). The three stimuli were presented randomly with an inter-stimulus interval that varied randomly between 1000-3000 ms. Participants were encouraged to take breaks between blocks to preserve focus and prevent fatigue or restlessness. Participants completed between 9 and 11 blocks (the majority completed 10) of 100 trials each with auditory, visual, and audio-visual stimuli randomly presented in each block. Only auditory-alone trials are considered for the current analyses.

\section{Auditory ERP Analysis}

EEG data were analyzed using MATLAB (MATLAB r2020b, MathWorks, Natick, MA) and custom in-house scripts. A low-pass filter of $45 \mathrm{~Hz}$ with a slope of $24 \mathrm{~dB} /$ octave, and a highpass filter of $1.6 \mathrm{~Hz}$ (Brandwein et al., 2013, 2015) with a slope of $12 \mathrm{~dB} /$ octave were applied to each participant's continuous EEG. Event related potentials (ERPs) for the auditory-alone condition were created by dividing the EEG into $600 \mathrm{~ms}$ epochs, including a $100 \mathrm{~ms}$ period prior to stimulus onset ( $-100 \mathrm{~ms}$ to $500 \mathrm{~ms}$ ). Baseline was defined as -100 to $0 \mathrm{~ms}$ relative to stimulus onset. Only trials for which the participant pressed the response button were included. Four participants in the ASD group were removed due to having fewer than 100 auditory trials. Additional participants (7 ASD, 5 NT) were excluded due to excessive electromuscular activity, measured by channels having an amplitude over $\pm 100 \mu \mathrm{V}$. Lastly, to detect outliers, we first calculated the maximum amplitude of Global Field Power (i.e., GFP; the standard deviation of all channels) for each subject. Subjects with maximum GFP values that were more than three standard deviations from the mean were excluded (14 ASD, 17 NT). This three-part rejection procedure excluded $18 \%$ of our original total dataset (21.9\% of ASD group, $15.5 \%$ of NT group), leading to our final sample of 89 (72 males, 17 females) ASD participants and 120 (55 
males, 65 females) NT participants. For this sample, average number of auditory trials per participant were 288 in the ASD group and 289 trials in the NT group.

The resulting AEPs were referenced to an average of all electrodes. For each participant, electrophysiological indices of early auditory processing were guided by predetermined latency windows over predetermined scalp regions informed by the literature on AEPs (Leavitt et al., 2007, 2011; Shafer et al., 2015). Time-windows and electrodes of interest confirmed (and adjusted if needed) through inspection of the group-averaged ERPs across the dataset. The N1 of the AEP, which we focus on here, can be parsed into subcomponents with positive and negative deflections peaking between $\sim 70$ and $175 \mathrm{~ms}$ and with foci over temporal and frontocentral scalp regions. The temporal responses are referred to as the T-complex and include the Ta, a first positive peak, and the $\mathrm{Tb}$, a subsequent negative going response (Tonnquist-Uhlen et al., 2003; Wolpaw \& Penry, 1975). A fronto-centrally focused negativity that peaks at about $100 \mathrm{~ms}$ is commonly referred to as the N1b (Näätänen \& Picton, 1987). Due to previous literature demonstrating group effects in the early auditory response, we focused on these three responses (Brandwein et al., 2013; Bruneau et al., 2003; Orekhova et al., 2009; Williams et al., 2020). For ease of distinction, we refer to these three responses as Ta, Tb, and N1b. For statistical tests analyzing group differences, AEPs were analyzed by region and hemisphere, through left and right temporal channels at 100-125ms and 150-175ms (Ta and Tb, respectively), and through the left and right channels over frontal-central scalp (for a balanced analysis; the fronto-central response tends to be centrally focused, and these right and left channels together are representative of this fronto-central focal region) at 100-125ms (N1b). See Table 1 for electrodes and latency windows used for analysis. For analyses investigating AEP associations with age, severity, and adaptive behavior, the frontocentral $\mathrm{N} 1 \mathrm{~b}$ was represented by averaging data from the two fronto-centrally placed electrodes (F1 and F2). Lateralization of the auditory response, which was indexed by taking the difference between the responses over left and right temporal scalp regions, was compared across groups for $\mathrm{Ta}$ and $\mathrm{Tb}$.

\begin{tabular}{ccc}
\hline Component & $\begin{array}{c}\text { Latency Window } \\
(\mathrm{ms})\end{array}$ & Electrodes \\
\hline Left Ta & $100-125$ & Tp7 \\
\hline Right Ta & $100-125$ & Tp8 \\
Left N1b & $100-125$ & F1 \\
Right N1b & $100-125$ & F2 \\
N1b & $100-125$ & F1,F2 \\
Left Tb & $150-175$ & Tp7 \\
Right Tb & $150-175$ & Tp8 \\
\hline
\end{tabular}

Table 1

Latency windows and electrodes used for a priori analysis.

\section{Statistical Analyses}

\section{Group differences in auditory responses}

Statistical analyses were implemented in R (RCoreTeam, 2014). Separate analyses were conducted for responses occurring at 100-125ms, encompassing both Ta and N1b, and for 150$175 \mathrm{~ms}$, reflecting the Tb components. For data from the 100-125ms window, a repeated measures ANCOVA was run to examine the main effects of group (ASD and NT), hemisphere 
(left and right), and region (frontal and temporal) on amplitude. For analyses of the data from the 150-175ms window, where only temporal responses were considered, a repeated measures ANCOVA with group and hemisphere as dependent variables was performed. Due to previous studies demonstrating changes in AEP amplitude throughout development in response to auditory stimuli (Pang \& Taylor, 2000; Ponton et al., 2000), age was added as a covariate in both of the ANCOVAs and included in results to further confirm these previous findings. In both of these models, lateralization was defined as the effect of hemisphere on amplitude. For both ANCOVAs, significant outliers were removed to fulfill ANCOVA assumptions. Since outliers can severely affect normality and homogeneity of variance (and ultimately the interpretation of the model), we identified (using a boxplot function in R) and excluded outliers before we ran the models. This process did not exclude a significant number of data points and did not delete entire subjects. Rather, it identified specific rows in the dataset that included outliers. For the repeated measures ANCOVA for 100-125ms, 13 rows were excluded from the 836 rows included in that dataset, and for the 150-175 ms ANCOVAs, 7 rows were excluded from the 418 total rows.

\section{Exploratory group analyses}

In the above analyses, the probability of Type-I errors was decreased by only considering responses in predetermined time-frames and electrodes. In order to provide a more complete description of our rich dataset, a secondary exploratory phase of analysis was conducted on the full dataset across 64 channels from $50 \mathrm{~ms}$ before stimulus onset to $300 \mathrm{~ms}$ post stimulus onset. This snapshot of the data allows us to identify potential group differences that were not identified in our a priori analysis and may serve to inform hypothesis generation for future studies. AEPs from the ASD and NT groups were compared using running two-tailed paired t-tests at $p \leq .05$ level. Effects lasting at least 16 consecutive ms were then presented in a statistical cluster plot (SCP). This thresholding criterion reduced the likelihood of a type-I error (Guthrie \& Buchwald, 1991; Molholm et al., 2002).

\section{Clinical associations}

To investigate the relationship between auditory responses and adaptive behavior (Vineland socialization, communication, and daily living scores), linear regression models were run for each AEP outcome. These separate models allowed us to better understand potential relationships between specific AEP components and behavior. Due to the aforementioned literature suggesting maturational changes in the AEP from early childhood into early adulthood, age was entered in the first step of the linear regression models.

\section{Results}

\section{Descriptive Statistics}

See Table 2 for participant characteristics of both ASD and NT subjects. Independent ttests demonstrated that there were no significant differences in age or PIQ between the ASD and NT groups $(t[207]=.14, p=.89)$ and $(t[193]=.13, p=.90)$, respectively. Due to literature suggesting a greater percentage of non-right-handedness in the ASD population (Rysstad \& Pedersen, 2016), and a potential effect of handedness on hemispheric lateralization in response to simple stimuli tasks (Papousek \& Schulter, 1999; Schmitz et al., 2019), we examined the frequency of left-handed participants in each group. There was a greater percentage of lefthanded participants in the ASD group (14.1\%) than in the NT group (7.5\%). However, chisquare analysis showed that this difference was not statistically significant, $X^{2}(2, N=192)=2.90$, $p=.24$. In the interest of representing the composition of our study participants, the 
demographics presented include variables that are not considered in our analyses. As can be seen, our sample was ethnically and racially diverse, although the largest proportion of participants were White (54\% of each group). It is also notable that chi-square analyses did not reveal significant group differences in maternal and paternal level of education or race/ethnicity between groups.

While there was a greater percentage of males (80\%) in the ASD group compared to the NT group (46\%), the male to female ratio in this ASD sample is consistent with asymmetry of males to females diagnosed with ASD in the general population (Loomes et al., 2017). However, this led to an imbalanced sex ratio between the groups. Therefore, clinical and electrophysiological dependent measures were run as a function of sex through independent $t$ tests and chi-square analyses in the NT group in order to assess whether there was evidence for an influence of sex on the auditory response in the NT group. Sex differences did not attain significance $(p>.05)$ for any of the dependent measures.

\begin{tabular}{|c|c|c|c|c|}
\hline & \multicolumn{2}{|c|}{ ASD } & \multicolumn{2}{|c|}{ NT } \\
\hline & Mean (SD) & Range & Mean (SD) & Range \\
\hline Total & 89 (17 females) & - & 120 (65 females) & - \\
\hline Age & $11.3(2.99)$ & $6.1-17.6$ & $11.1(3.00)$ & $6.0-17.5$ \\
\hline FSIQ & $102.3(17.2)$ & $70-158$ & $110.1(10.7)$ & $86-142$ \\
\hline$P I Q$ & $105.3(17.0)$ & $75-150$ & $104.9(11.1)$ & $77-134$ \\
\hline VIQ & $99.1(19.7)$ & $55-150$ & $112.4(11.0)$ & 89-141 \\
\hline Severity & $7.6(1.58)$ & $4-10$ & - & - \\
\hline \multicolumn{5}{|l|}{ Race/Ethnicity } \\
\hline White & $56.2 . \%$ & & $55.0 \%$ & \\
\hline Black & $18.0 \%$ & & $17.5 \%$ & \\
\hline $\begin{array}{l}\text { Asian/Pacific } \\
\text { Islander }\end{array}$ & $6.7 \%$ & & $.8 \%$ & \\
\hline $\begin{array}{c}\text { American } \\
\text { Indian/Native } \\
\text { Hawaiian }\end{array}$ & $1.1 \%$ & & - & \\
\hline Multiple Races & $7.9 \%$ & & $10.8 \%$ & \\
\hline Unknown & $10.1 \%$ & & $15.8 \%$ & \\
\hline \multicolumn{5}{|l|}{$\begin{array}{l}\text { Maternal } \\
\text { Education }\end{array}$} \\
\hline Graduate degree & $22.5 \%$ & & $25.8 \%$ & \\
\hline $\begin{array}{l}\text { Some graduate } \\
\text { school }\end{array}$ & $4.5 \%$ & & $.8 \%$ & \\
\hline College degree & $31.5 \%$ & & $23.3 \%$ & \\
\hline Some college & $18.0 \%$ & & $9.2 \%$ & \\
\hline $\begin{array}{l}\text { High school } \\
\text { diploma/ GED }\end{array}$ & $7.9 \%$ & & $10.8 \%$ & \\
\hline $\begin{array}{l}\text { Technical school/ } \\
\text { associates }\end{array}$ & $1.1 \%$ & & - & \\
\hline $\begin{array}{c}\text { Some school, no } \\
\text { degree }\end{array}$ & $3.4 \%$ & & $10.0 \%$ & \\
\hline $\begin{array}{l}\text { No formal } \\
\text { schooling }\end{array}$ & - & & $.8 \%$ & \\
\hline Unknown & $11.2 \%$ & & $19.2 \%$ & \\
\hline \multicolumn{5}{|l|}{$\begin{array}{l}\text { Paternal } \\
\text { Education }\end{array}$} \\
\hline Graduate degree & $21.3 \%$ & & $21.7 \%$ & \\
\hline $\begin{array}{c}\text { Some graduate } \\
\text { school }\end{array}$ & $1.1 \%$ & & $1.7 \%$ & \\
\hline
\end{tabular}




\begin{tabular}{ccc} 
College degree & $21.3 \%$ & $15.8 \%$ \\
\hline $\begin{array}{c}\text { Some college } \\
\text { High school } \\
\text { diploma/ GED }\end{array}$ & $9.0 \%$ & $7.5 \%$ \\
$\begin{array}{c}\text { Technical school/ } \\
\text { associates }\end{array}$ & $21.3 \%$ & $20.0 \%$ \\
$\begin{array}{c}\text { Some school, no } \\
\text { degree }\end{array}$ & $4.5 \%$ & - \\
$\quad 6.7 \%$ & $11.7 \%$ \\
$\begin{array}{c}\text { No formal } \\
\text { schooling }\end{array}$ & $1.1 \%$ & - \\
Unknown & $13.5 \%$ & $21.7 \%$ \\
\hline
\end{tabular}

\section{Table 2}

Participant characteristics (mean, range, and standard deviations) after rejection analysis. ASD and NT groups were matched on Performance IQ (PIQ). Verbal IQ (VIQ) and Full-Scale IQ (FSIQ) were significantly different between ASD and NT groups.

\section{Behavioral Results}

Mean hit rates and RTs significantly differed between ASD and NT groups. The ASD group exhibited longer RTs $(\mathrm{ASD}=488.98 \mathrm{~ms}, \mathrm{NT}=435.17 \mathrm{~ms}), t(207)=-2.76, p=.006, d=$ $.16)$ and lower hit rates $(\mathrm{ASD}=86.35 \%, \mathrm{NT}=91.39 \%), t(297)=3.30, p=.001, d=-.45)$ compared to the NT group.

\section{Electrophysiological Results}

The morphology of the AEPs appeared to be highly similar between the ASD and NT groups (see Figures 1 and 2), with a positive-going response peaking at $\sim 100 \mathrm{~ms}$ (Ta) over bilateral temporal scalp regions, a fronto-central negative-going response peaking at $\sim 100 \mathrm{~ms}$ (N1b), and a bilateral temporal negative-going response peaking at $\sim 150 \mathrm{~ms}$ (Tb). Nevertheless, visual comparison suggested small group differences in the amplitude of the response over temporal scalp regions. Topographical mapping also suggested rightward lateralization of the response between $75-125 \mathrm{~ms}$ in both groups, that appeared to be stronger in the NT group.

\section{Group differences}

100-125ms latency window. Levene's test for equality of variances was significant, and thus we could not assume the data were homogeneous. Therefore, the ANCOVA analysis was adjusted for heteroscedasticity using a coefficient corrected matrix. The ANCOVA revealed significant main effects of age, hemisphere and region $\left(F(1,807)=21.92, p<.001, \eta^{2}=.007, F(1,807)=\right.$ $7.99, p=.005, \eta^{2}=.008$, and $F(1,807)=5663.80, p<.001, \eta^{2}=.33$, respectively). No significant group main effects or interactions were observed. In line with developmental effects on the AEP, there was a significant age $\times$ region interaction, $F(1,807)=41.59, p<.001, \eta^{2}=.032$. To further explore this interaction, Spearman correlations were run for the total sample between age and amplitude for each region. Ta and N1b were calculated as an average of the left and right channels. N1b and age were significantly negatively correlated, $r_{s}=-.35, p<.001$ reflecting that the N1b became more negative as age increased. The Ta and age correlation did not reach significance, $r_{s}=.089, p=.20$. Figure 3 depicts the relationship between age and both N1b and Ta. A second interaction was found for hemisphere and region, $F(1,807)=16.13, p<.001, \eta^{2}$ $=.013$. Estimated marginal means demonstrated that the temporal region had the highest difference in amplitude between left and right hemispheres (left $=1.40$, right $=2.48$ ) compared to the frontal region $(\mathrm{left}=-1.08$, right $=-1.21$ ). This significant hemisphere $\times$ region interaction reflects the rightward lateralization of the response over temporal scalp for the total sample. While this was numerically larger in the NT group (see Table 3), this did not reach significance. 

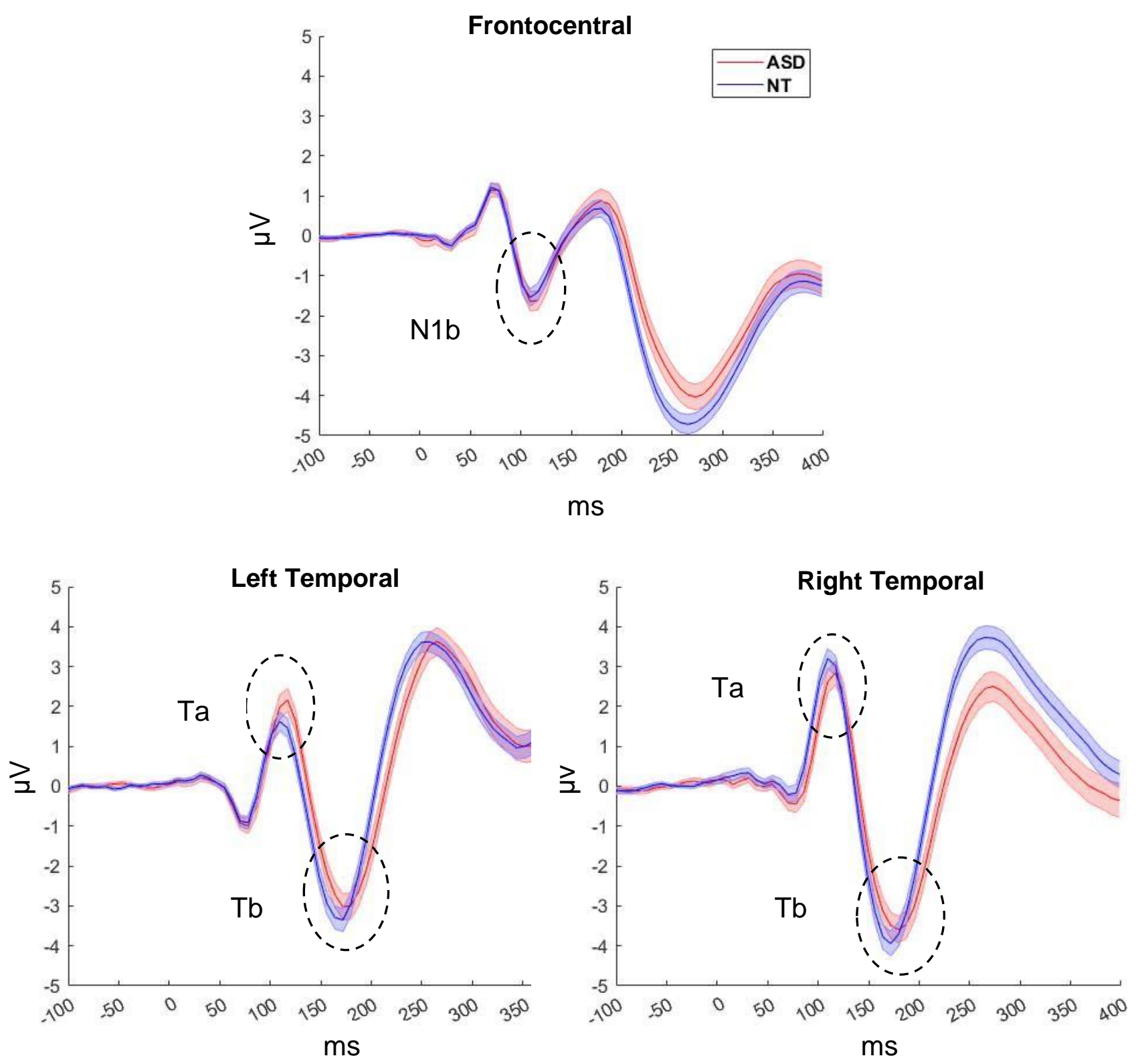

Figure 1.

AEP waveforms of mean amplitude for both groups over frontocentral (average of F1 and F2), left temporal (Tp7), and right temporal (Tp8) regions. 
ASD

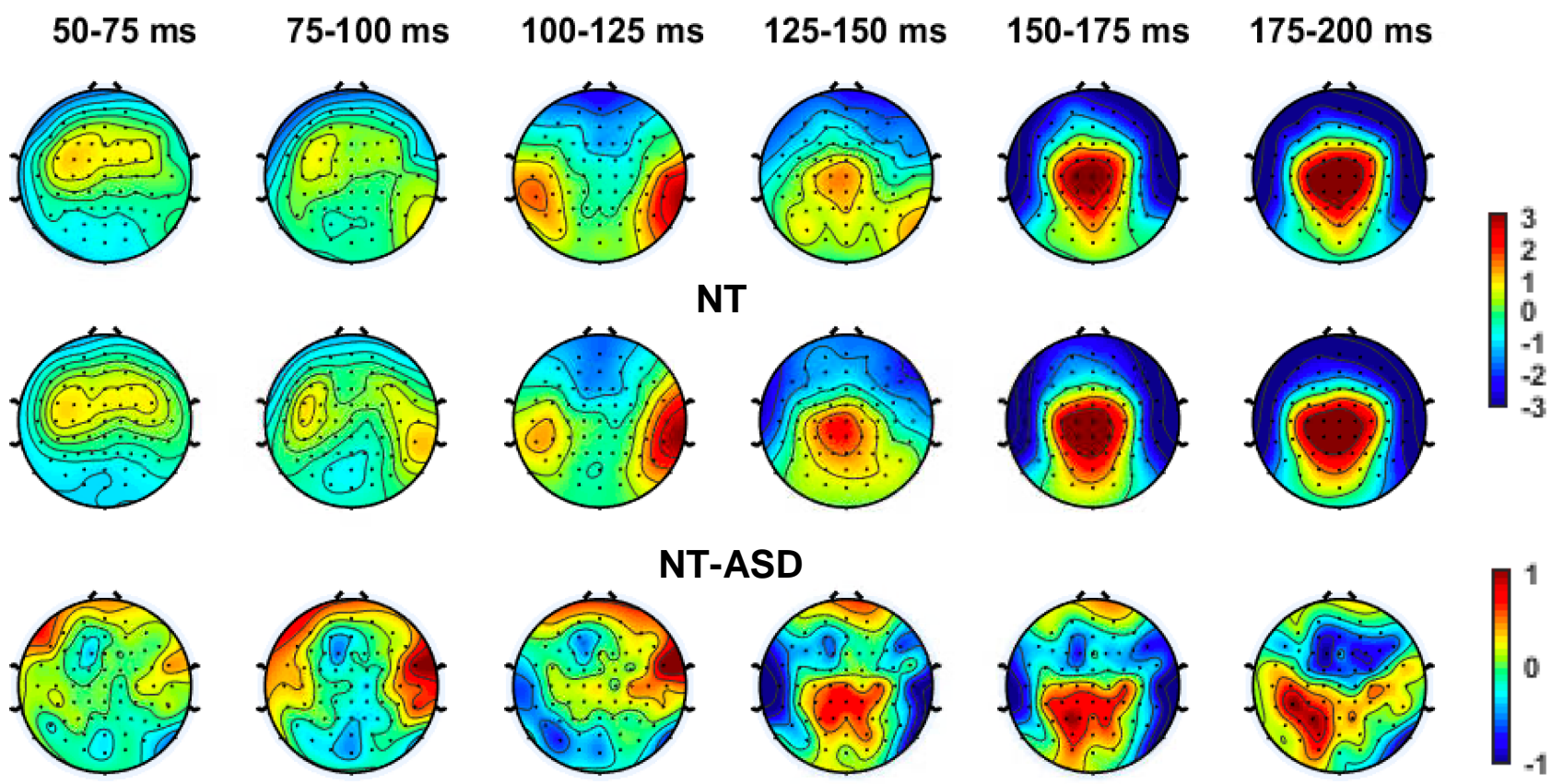

Figure 2

Topographical maps depicting average amplitude of the auditory responses in $25 \mathrm{~ms}$ steps from 50-200 ms for ASD, NT, and the difference between ASD and NT. The color bar depicts amplitude in $\mu \mathrm{V}$.
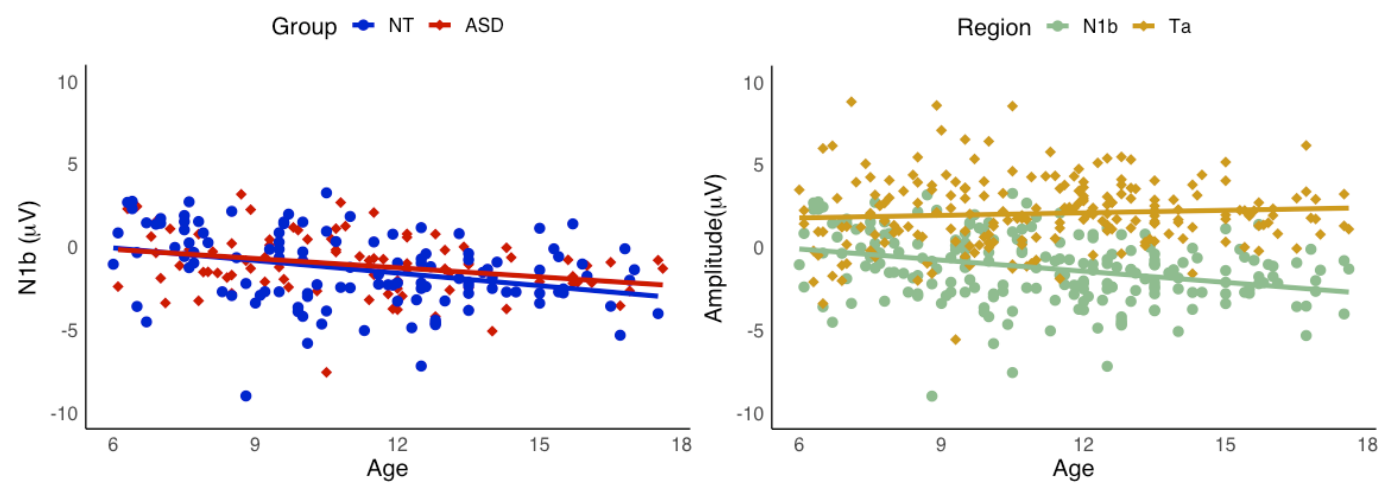

Figure 3.

Left panel: Scatterplot of N1b and age by group. Right panel: Scatter plots of N1b and Ta by age group, for total sample. $\mathrm{N} 1 \mathrm{~b}$ and age were significantly related $\left(\mathrm{r}_{\mathrm{s}}=-.35, p<.001\right)$.

150-175ms latency window. Analysis of responses over temporal scalp regions $(\mathrm{Tb})$ revealed a main effect of group $\left(F(1,403)=7.72, p=.006, \eta^{2}=.018\right)$ indicating that the ASD 
group displayed a decreased (less negative) auditory response over temporal scalp regions compared to the NT group. A main effect of hemisphere was also significant $(F(1,403)=4.48$, $\left.p=.03, \eta^{2}=.011\right)$ due to larger responses over right compared to left temporal scalp regions. The group $\mathrm{x}$ hemisphere interaction did not reach significance, $\left(F(1,403)=.056, p=.81, \eta^{2}=.004\right)$. Table 3 displays mean amplitudes by group across hemisphere and region for each time frame analyzed. The ANCOVA did not demonstrate a significant effect for age.

\begin{tabular}{ccccc}
\hline Window & Region & Hemisphere & ASD Mean (SD) & NT Mean (SD) \\
\hline \multirow{2}{*}{$100-125 m s$} & \multirow{2}{*}{ Frontal (N1b) } & Left & $-.92(1.91)$ & $-1.24(2.22)$ \\
& & Right & $-1.17(1.77)$ & $-1.23(2.24)$ \\
& \multirow{2}{*}{ Temporal (Ta) } & Left & $1.52(2.22)$ & $1.29(2.40)$ \\
& & Right & $2.41(2.15)$ & $2.56(2.25)$ \\
& \multirow{2}{*}{ Te-175ms } & Left & $-2.14(2.46)$ & $-2.81(2.70)$ \\
& & Right & $-2.62(2.51)$ & $-3.40(2.71)$ \\
\hline
\end{tabular}

Table 3.

Mean amplitudes of auditory responses over left and right frontal and temporal scalp regions (Ta, $\mathrm{N} 1 \mathrm{~b}$, and $\mathrm{Tb})$.

\section{Exploratory group analyses}

Exploratory analysis using the SCP approach suggested early group differences in the 93 to $109 \mathrm{~ms}$ window over bilateral temporal/frontal-temporal scalp (channels T7, FT7, FC5; T8, FT8, FC6; see Figure 4), at a time window slightly earlier than the 100-125ms window used in our a priori analysis. Notably, these channels overlapped with the temporal scalp region (and channels) used in our a priori analyses. A post hoc ANCOVA was run to confirm this effect with hemisphere and group as independent variables and age as a covariate. A repeated measures ANCOVA was performed on the average amplitude in the 93-109ms window, for averaged data from right and left channels (T8, FT8, FC6 and T7, FT7, FC5 respectively). There were significant group and hemisphere effects, $F(1,398)=9.01, p=.002, \eta^{2}=.021$, and $F(1,398)=$ $9.15, p=.003, \eta^{2}=.022$, respectively, and a significant group $\mathrm{x}$ hemisphere interaction, $F(1,398)$ $=4.24, p=.04, \eta^{2}=.01$, due to larger differences between left and right temporal regions in the NT group than the ASD group. See Figures 5 and 6 for plots of significant group differences.






\section{Figure 4}

Statistical cluster plots between ASD and NT groups, from 0 to $300 \mathrm{~ms}$. The color bar represents significant differences between ASD and NT groups, from $p=.05$ to $p<.001$. The red box delineates the 93-109 ms window noted in the text. Channels are grouped by region.
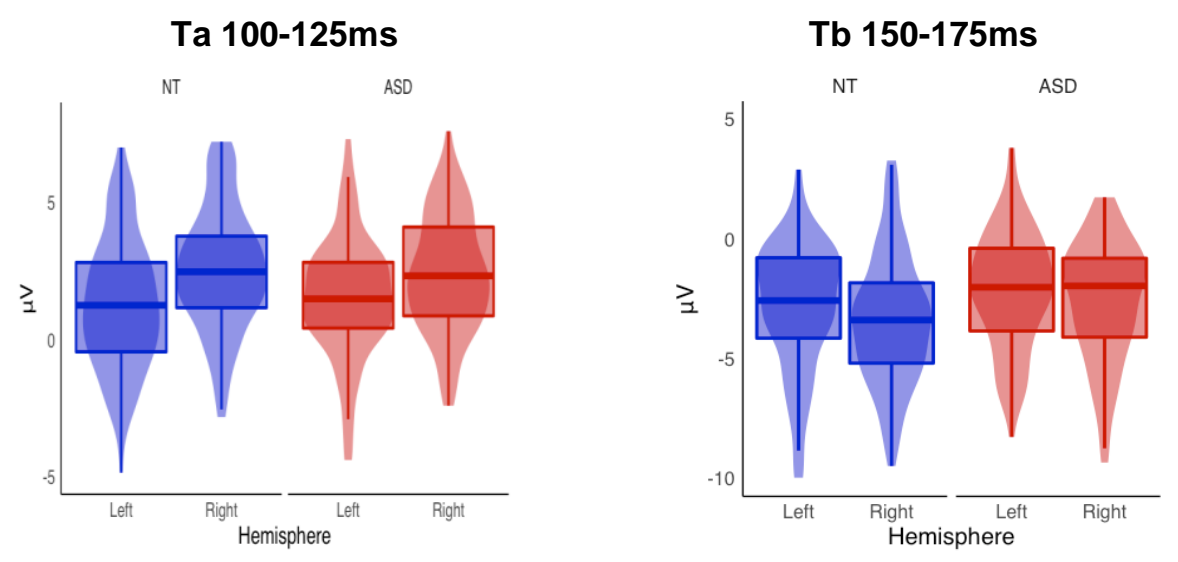

Post Hoc Ta 93-109ms

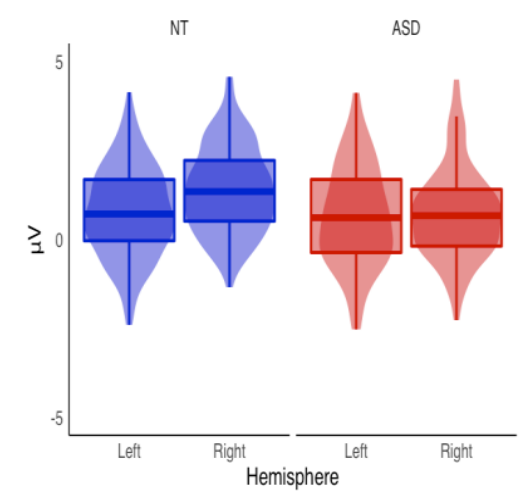

Figure 5

Top panel: Mean amplitudes of Ta and Tb for ASD and NT groups for left and right hemispheres. Bottom panel: Mean amplitudes for ASD and NT groups from post hoc analysis. Scales were adjusted to illustrate distribution. 


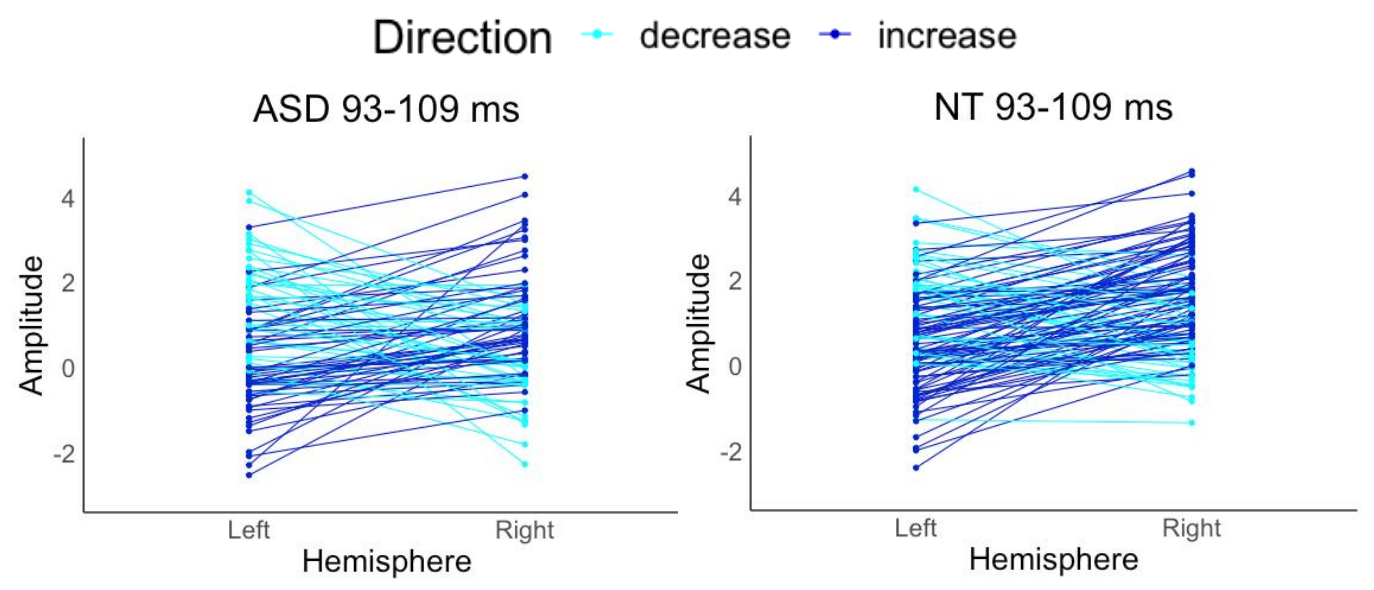

Figure 6.

Mean ERPs for each participant across left and right hemispheres in the exploratory post hoc data. The ASD group demonstrated diminished responses in the right hemisphere compared to the NT group.

\section{Associations between Clinical Measures and Auditory Responses}

14 participants in the ASD group and 35 participants in the NT group did not have Vineland scores. Therefore, a subset of this sample consisting of 74 ASD and 44 NT participants, matched on age (range of 6.0-17.5) and IQ (ASD = 102.8; NT = 109.6) was used to investigate the predictive value of measures of adaptive behavior on auditory responses. Chi-square analyses and independent t-tests run between this subset and the participants without Vineland scores did not reveal significant differences on clinical or electrophysiological measures. Within the subset, Vineland scores were significantly lower for the ASD group than the NT group for the communication, socialization, and daily living sub-domains, as well as for the total adaptive behavior composite score, all with p values <.001(see Figure 7).

Hierarchical linear regression models with age in the first step and clinical measures in the second step were run for each AEP measure across both NT and ASD groups. Models were run for left hemisphere, right hemisphere, and lateralization response for both responses over bilateral temporal regions ( $\mathrm{Ta}$ and $\mathrm{Tb}$ ). To ensure that group differences in AEP responses or Vineland measures did not inflate relationships between Vineland domains and AEPs, hierarchical regressions that were significant were conducted separately for ASD and NT groups.

\section{The Ta Component}

For left Ta, Vineland domains of communication, daily living, and socialization were not significant predictors $(F(4,113)=2.33, p=.06)$. The total model contributed $7.6 \%$ of variance in left Ta amplitude. For right Ta, Vineland domains were not significant predictors $(F(4,113)=$ $2.32, p=.06)$. The total model contributed $7.6 \%$ of variance in right Ta amplitude. For Ta lateralization, the model was significant, $F(4,113)=5.57, p<.001$, contributing $16.5 \%$ of variance $(p<.001)$, with Vineland communication and daily living as significant predictors, $B=-.087$, $t(113)=-4.24, p<.001$ and $B=.051, t(113)=2.61, p=.01$, respectively. Notably, using the data from the exploratory post hoc analysis (93-109ms) yielded similar results, with Vineland 
communication and daily living significantly predicting Ta lateralization $(B=-.052, t(113)=$ $-3.22, p=.002$ and $B=.045, t(113)=2.92, p=.004$, respectively.
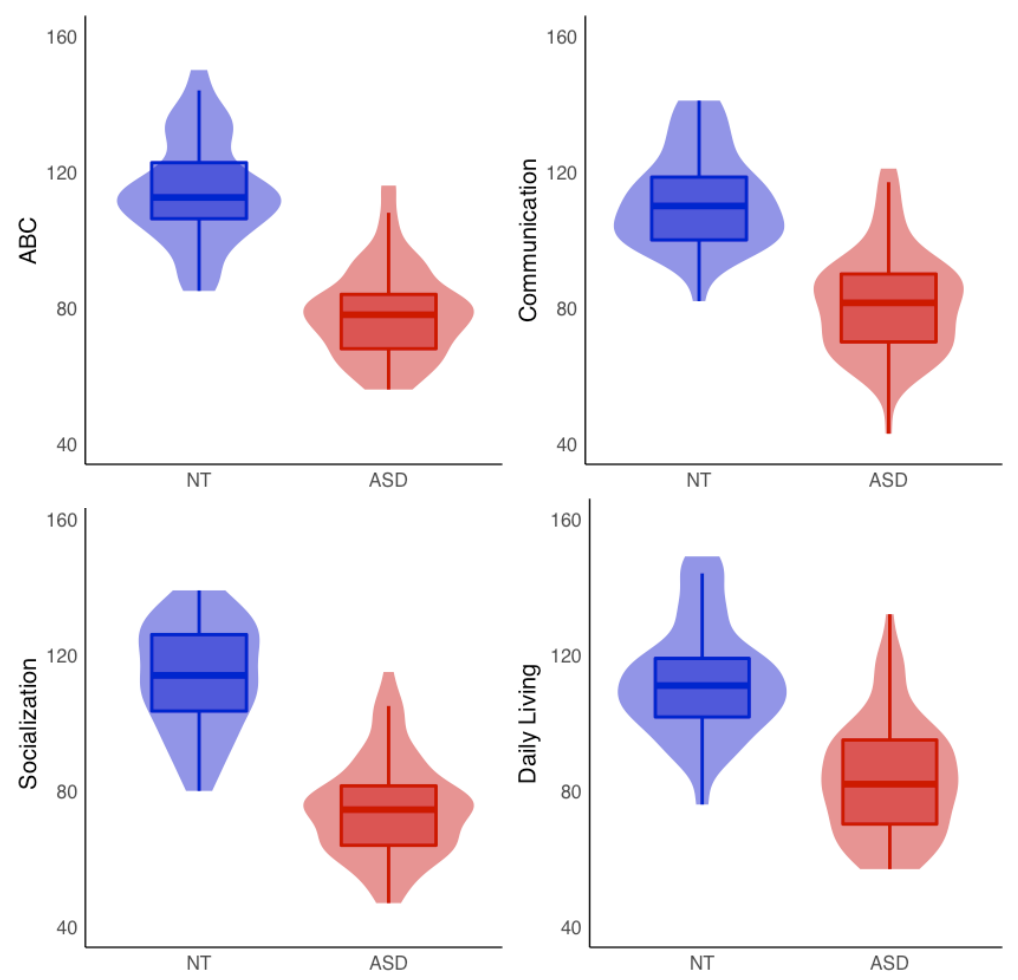

Figure 7.

Violin plots of ASD and NT groups for each Vineland domain and total adaptive behavior composite $(\mathrm{ABC})$ score.

\section{The N1b Component}

For N1b, the model was significant, $F 4,113)=2.74, p=.032$, with age as a significant predictor, $B=-.23, t(113)=-3.14, p=.002$, and the Vineland domains contributing only a nonsignificant additional $1.1 \%$ variance $(p=.22)$.

\section{The Tb Component}

For left $\mathrm{Tb}$, the total model contributed $4.5 \%$ of variance, and the model was not significant for Vineland domains $(F(4,113)=1.33, p=.27)$. For right $\mathrm{Tb}$, the total model contributed $4.6 \%$ of variance, and also did not reach significance for Vineland domains $(F(4$, $113)=1.37, p=.25)$. For Tb lateralization, the model was significant, $F(4,113)=2.60, p=.04$, contributing $8.4 \%$ of variance $(p=.06)$, with Vineland communication as a significant predictor, $B=-.08, t(113)=-45, p=.009$. 


\section{Individual ASD- and NT- group analyses}

Autism Spectrum Disorder Group. For Ta lateralization in the ASD group, the model was significant after the inclusion of the Vineland domains in the second step, $F(4,69)=3.16$, $p=.019$, contributing $15.5 \%$ in variance $(p=.01)$. In this model, Vineland communication and daily living were significant predictors, $B=-.093, t(69)=-3.18, p=.003$, and $B=.007, t(69)$ $=2.99, p=.003$, respectively. The models were not significant for N1b or Tb lateralization.

Neurotypical Group. Models were not significant in the NT group for $\mathrm{Ta}$ or $\mathrm{Tb}$ lateralization, or N1b. See Figure 8 for residual plots between Ta responses and Vineland domains by group.

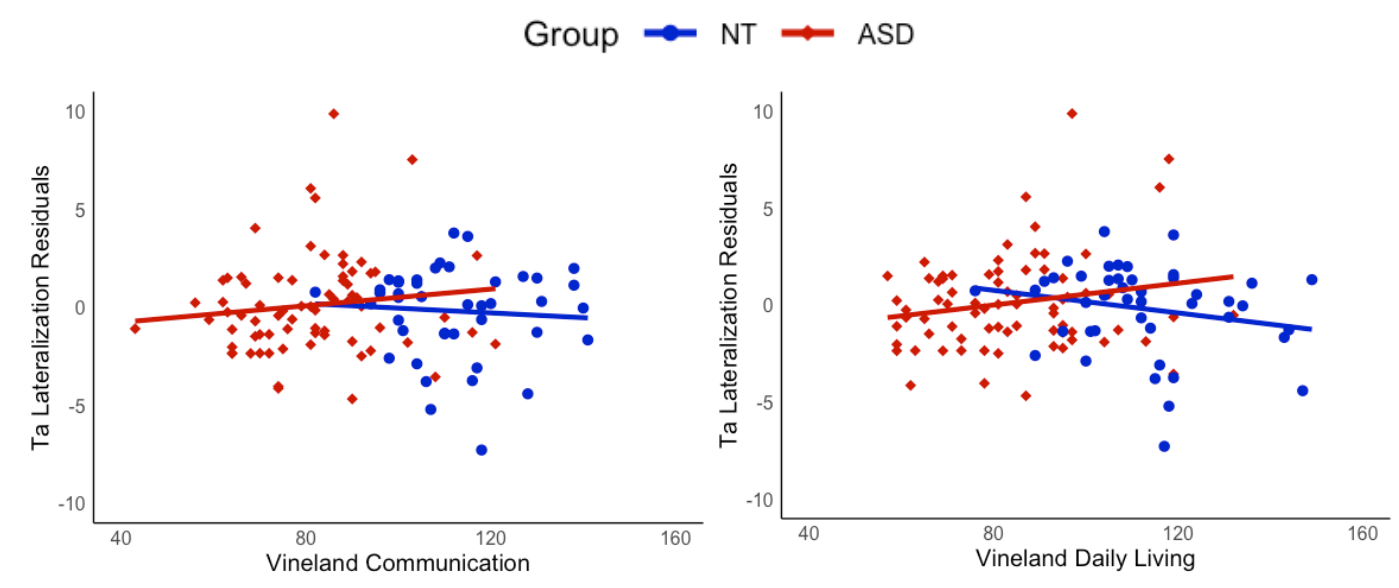

Figure 8.

Partial residual plots of Ta amplitude and Vineland communication and daily living. 


\section{Discussion}

Engagement in age appropriate adaptive behaviors in everyday situations is significantly reduced in ASD (American Psychiatric Association, 2013). Prior research focusing on electrophysiological responses to auditory stimuli suggests that children and adolescents with ASD exhibit atypical auditory responses (Brandwein et al., 2013; Bruneau et al., 2003; JanssonVerkasalo et al., 2003; Orekhova et al., 2009; Stroganova et al., 2013). However, how atypical auditory responses are related to adaptive behaviors has not been extensively studied. The current analyses extend our understanding of the relationship between auditory cortical processing and clinical phenotype in ASD by showing that greater rightward lateralization of the early AEP over temporal scalp was associated with better communication and daily living adaptive scores.

With regard to group differences, the ASD group exhibited significantly diminished AEP responses to tones in the $150-175 \mathrm{~ms}$ timeframe over bilateral temporal scalp regions.

Diminished AEPs align with our previous work (Brandwein et al., 2013) as well as findings from other groups in which responses between 100 and 200ms were of smaller amplitude in ASD compared to control groups (Bruneau et al., 2003; Orekhova et al., 2009b; Williams et al., 2020). While a priori testing of differences for an earlier epoch of 100-125ms failed to reach significance, more comprehensive post hoc consideration of the data supported group differences in a slightly earlier time frame of 93-108. Consistent with previous studies (Brandwein et al., 2013; Gomes et al., 2001; Ponton et al., 2000), age was significantly related to the N1b response in both groups; however this did not interact with group, thus failing to reveal an interaction between childhood development and atypical auditory processing in ASD.

Both groups exhibited the expected rightward lateralization of the AEP to tones. While this lateralization appeared to be reduced in the ASD group (see the 100-125 ms topography maps in Figure 2), this difference did not hold up to statistical testing in our primary analyses. Tellingly, however, the lateralization index derived from the same data revealed a significant relationship with adaptive behavior in the ASD group. This suggests that altered lateralization is an informative feature of ASD, especially when considered at the individual rather than group level. Furthermore, post hoc analysis on a slightly earlier time window supported the presence of altered lateralization in ASD. In prior work from our lab we found atypical lateralization in ASD during a selective attention visual object processing task (Fiebelkorn et al., 2013), and altered lateralization has been observed in language and motor studies (see e.g., (Floris et al., 2016; Leung et al., 2019; Lin et al., 2018; Nickl-Jockschat et al., 2015)). Roberts and colleagues also identified hemisphere specific processing differences in ASD, with the delay in the magnetic auditory evoked response to tones more robust in the right compared to the left auditory cortex in individuals with ASD (Roberts et al., 2019). The finding of altered lateralization across sensory and motor processing and for both language and non-language stimuli suggests a weakening of the hemispheric specialization that is seen in typical development (Floris et al., 2021). As such, this may be a prominent feature of altered neurodevelopment in ASD. Importantly, in line with the idea that greater extent of atypical neural development is likely to be associated with greater clinical severity, our analyses further revealed that greater lateralization of responses to auditory 
tones was associated with better adaptive functioning in the communication and daily living domains in individuals with ASD.

In addition to the role of aberrant neurodevelopment, how might disruption of auditory processing itself lead to behavioral and perceptual/cognitive sequelae, and in particular delayed development of adaptive behavior? The Vineland daily living domain includes items such as getting dressed or putting away toys. These activities may evoke altered auditory brain responses and specific auditory sensitivities in a child with ASD, preventing them from efficiently completing daily living tasks and developing appropriate adaptive skills. Indeed, hyper- or hyporeactivity to sensory stimuli is characteristic of ASD (American Psychiatric Association, 2013), and is associated with poorer adaptive behavior (Feldman et al., 2020; Lane et al., 2010; O'Donnell et al., 2012; Rogers et al., 2003). The Vineland communication domain, comprised of subdomains of receptive, expressive and written communication, inherently involves speech and language skills, which are notably impaired in individuals with ASD (Foxe et al., 2015; Lai et al., 2014; Ross et al., 2015). Previous research indicates associations between longer latency MEG responses to auditory tones over the right hemisphere and language ability, as measured by verbal IQ (Matsuzaki, Ku, et al., 2019), as well as Vineland communication skills (Roberts et al., 2019), and between amplitude of the early response and performance during a learned language task in ASD (Arnett et al., 2018). Atypical auditory processing could lead to avoidant reactions to speech, or impair the ability to develop typical communication skills. More research is needed to unpack the respective roles of altered neurodevelopment and atypical auditory processing for adaptive skills.

It is important to note that although a large number of studies investigating early auditory cortical processing in ASD have demonstrated atypical responses in ASD groups compared to NT groups (Brandwein et al., 2013; Bruneau et al., 2003; Jansson-Verkasalo et al., 2003; Matsuzaki, Ku, et al., 2019; E. V. Orekhova et al., 2009; Roberts et al., 2019; Stroganova et al., 2013), these group differences are often modest and the specific results are heterogeneous across studies (Williams et al., 2020), with some studies finding little or no differences (Knight et al., 2020). ASD has a strong genetic basis that is, in most cases, polygenic and variable across individuals (Ramaswami \& Geschwind, 2018). Furthermore, unsurprisingly, risk associated allelic variants tend to implicate neurobiological pathways involved in fetal neural development and synaptic function (de la Torre-Ubieta et al., 2016). Consistent with this heterogeneity, prior work suggests that atypical connectivity in sensory and higher order networks in ASD is highly idiosyncratic compared to controls (Benkarim et al., 2021; Hahamy et al., 2015). Thus, while the auditory cortex appears particularly vulnerable to resulting neuropathology, just how this plays out may vary based on an individual's genetic background, specific set of genetic vulnerabilities, and the environmental factors that they are exposed to.

\section{Conclusions}

This study supports prior findings that children and adolescents with ASD exhibit atypical auditory responses at the neural level. Furthermore, our results support a relationship 
between atypical auditory processing in children and adolescents with ASD and adaptive behavior. Although there is great heterogeneity in the ASD population, these findings utilizing a large dataset with a wide range of ages indicate the presence of a relationship between basic neuropathological processes and maladaptive behavior in this population. Future studies will be needed to understand how this knowledge can inform approaches to improving adaptive function in this group, especially in the domains of communication and daily living skills. Furthermore, expanding the group to include minimally verbal and nonverbal indiviuals with ASD will be an important step to expanding understanding of how auditory processing differences contribute to adaptive behavior and other aspects of the autism clinical phenotype. 
ADI-R: Autism Diagnostic Interview-Revised

AEMF: Auditory evoked magnetic fields

ASD: Autism spectrum disorder

ADOS-2: Autism Diagnostic Observation Schedule-2

EEG: Electroencephalography

ERP: Event related potential

FSIQ: Full-scale intelligence quotient

MEG: Magnetoencephalography

NT: Neurotypical

PIQ: Performance intelligent quotient

VIQ: Verbal intelligent quotient

WASI-II: Weschler Abbreviated Scale of Intelligence, Second Edition

AEP: Auditory Evoked Potential

SCP: Statistical Cluster Plot

ABC: Adaptive Behavior Composite

RT: Reaction Time

\section{Declarations}

\section{Ethics approval and consent to participate}

All procedures were approved by the Institutional Review Boards of the Albert Einstein College of Medicine, the City College of New York, and the Graduate Center of the City University of New York and were in accord with the ethical standards as stated in the Declaration of Helsinki.

\section{Consent for publication}

Not applicable.

\section{Availability of data and materials}

Data from the findings of this study are available from the authors upon request. The authors will make the Matlab scripts available in a public repository (Github).

\section{Competing interests}

The authors have declared that no competing interests exist.

\section{Funding}

Primary funding for this work was provided through a grant from the U.S. National Institute of Mental Health (MH085322 to S.M. and J.J.F.). The Human Clinical Phenotyping Core, where the majority of the children enrolled in this study were clinically evaluated, is a facility of the Rose F. Kennedy Intellectual and Developmental Disabilities Research Center (IDDRC) which is funded through a center grant from the Eunice Kennedy Shriver National Institute of Child Health \& Human Development (NICHD P30 HD071593; U54 HD090260; P50 HD105352). Work on ASD at the University of Rochester (UR) collaborating site is funded by a center grant from the Eunice Kennedy Shriver National Institute of Child Health and Human Development 
(NICHD P50 HD103536) supporting the UR Intellectual and Developmental Disabilities Research Center (UR-IDDRC).

\section{Authors' contributions}

Conceived and designed the study: J.J.F. and S.M. Data analysis: M.C., S.T., A.A.F., and M.J.C. Supervision: S.M. Writing- original manuscript preparation: M.C. and S.M. Writing- review and editing: S.M., A.A.F., S.T., L.O., M.C., M.J.C. and J.J.F. All authors read and approved the final manuscript.

Acknowledgments: We extend our deep appreciation to all of the families that have generously given their time to participate in this research. This work could not be done without the clinicians that have performed or supervised clinical and cognitive testing including: Alice Brandwein; Juliana Bates; Hilary Gomes, and Natalie Russo. We are grateful to the research assistants and technicians that have put in great efforts to collect high quality EEG data while ensuring the comfort of our participants, including: Douwe Horsthuis, Alaina Berruti, Frantzy Acluche, Greg Peters, Sarah Ruberman, and Elise Taverna. An earlier version of this manuscript was submitted to the Department of Psychology at Fordham University towards fulfillment of the first author's master's degree.

\section{Corresponding Author}

Correspondence to Sophie Molholm: sophie.molholm@einsteinmed.edu 


\section{References}

American Psychiatric Association (Ed.). (2013). Diagnostic and statistical manual of mental disorders: DSM-5 (5th ed). American Psychiatric Association.

Arnett, A. B., Hudac, C. M., DesChamps, T. D., Cairney, B. E., Gerdts, J., Wallace, A. S., Bernier, R. A., \& Webb, S. J. (2018). Auditory perception is associated with implicit language learning and receptive language ability in autism spectrum disorder. Brain and Language, 187, 1-8. https://doi.org/10.1016/j.band1.2018.09.007

Benkarim, O., Paquola, C., Park, B., Hong, S.-J., Royer, J., Vos de Wael, R., Lariviere, S., Valk, S., Bzdok, D., Mottron, L., \& C. Bernhardt, B. (2021). Connectivity alterations in autism reflect functional idiosyncrasy. Communications Biology, 4(1), 1-15. https://doi.org/10.1038/s42003-021-02572-6

Berretz, G., Wolf, O. T., Güntürkün, O., \& Ocklenburg, S. (2020). Atypical lateralization in neurodevelopmental and psychiatric disorders: What is the role of stress? Cortex; $a$ Journal Devoted to the Study of the Nervous System and Behavior, 125, 215-232. https://doi.org/10.1016/j.cortex.2019.12.019

Bishop, D. V. M. (2013). Cerebral asymmetry and language development: Cause, correlate, or consequence? Science (New York, N.Y.), 340(6138), 1230531. https://doi.org/10.1126/science.1230531

Brandwein, A. B., Foxe, J. J., Butler, J. S., Frey, H. P., Bates, J. C., Shulman, L., \& Molholm, S. (2015). Neurophysiological indices of atypical auditory processing and multisensory integration are associated with symptom severity in autism. Journal of Autism and Developmental Disorders, 45(1), 230-244. https://doi.org/10.1007/s10803-014-2212-9 
Brandwein, A. B., Foxe, J. J., Butler, J. S., Russo, N. N., Altschuler, T. S., Gomes, H., \& Molholm, S. (2013). The Development of Multisensory Integration in High-Functioning Autism: High-Density Electrical Mapping and Psychophysical Measures Reveal Impairments in the Processing of Audiovisual Inputs. Cerebral Cortex, 23(6), 13291341. https://doi.org/10.1093/cercor/bhs109

Bruneau, N., Bonnet-Brilhault, F., Gomot, M., Adrien, J.-L., \& Barthélémy, C. (2003). Cortical auditory processing and communication in children with autism:

Electrophysiological/behavioral relations. International Journal of Psychophysiology, 51(1), 17-25. https://doi.org/10.1016/S0167-8760(03)00149-1

Carter, A. S., Volkmar, F. R., Sparrow, S. S., Wang, J. J., Lord, C., Dawson, G., Fombonne, E., Loveland, K., Mesibov, G., \& Schopler, E. (1998). The Vineland Adaptive Behavior Scales: Supplementary norms for individuals with autism. Journal of Autism and Developmental Disorders, 28(4), 287-302. https://doi.org/10.1023/a:1026056518470

Crosse, M. J., Foxe, J. J., \& Molholm, S. (2019). Developmental Recovery of Impaired Multisensory Processing in Autism and the Cost of Switching Sensory Modality [Preprint]. Neuroscience. https://doi.org/10.1101/565333

Cuppini, C., Ursino, M., Magosso, E., Crosse, M. J., Foxe, J. J., \& Molholm, S. (2020). Crosssensory inhibition or unisensory facilitation: A potential neural architecture of modality switch effects. Journal of Mathematical Psychology, 99, 102438. https://doi.org/10.1016/j.jmp.2020.102438

De Guibert, C., Maumet, C., Jannin, P., Ferré, J.-C., Tréguier, C., Barillot, C., Le Rumeur, E., Allaire, C., \& Biraben, A. (2011). Abnormal functional lateralization and activity of 
language brain areas in typical specific language impairment (developmental dysphasia).

Brain, 134(Pt 10), 3044-3058. https://doi.org/10.1093/brain/awr141

de la Torre-Ubieta, L., Won, H., Stein, J. L., \& Geschwind, D. H. (2016). Advancing the understanding of autism disease mechanisms through genetics. Nature Medicine, 22(4), 345-361. https://doi.org/10.1038/nm.4071

Dubois, J., Hertz-Pannier, L., Cachia, A., Mangin, J. F., Le Bihan, D., \& Dehaene-Lambertz, G. (2009). Structural asymmetries in the infant language and sensori-motor networks. Cerebral Cortex (New York, N.Y.: 1991), 19(2), 414-423. https://doi.org/10.1093/cercor/bhn097

Edgar, J. C., Fisk Iv, C. L., Berman, J. I., Chudnovskaya, D., Liu, S., Pandey, J., Herrington, J. D., Port, R. G., Schultz, R. T., \& Roberts, T. P. L. (2015). Auditory encoding abnormalities in children with autism spectrum disorder suggest delayed development of auditory cortex. Molecular Autism, 6, 69. https://doi.org/10.1186/s13229-015-0065-5

Fair, D. A., Dosenbach, N. U. F., Church, J. A., Cohen, A. L., Brahmbhatt, S., Miezin, F. M., Barch, D. M., Raichle, M. E., Petersen, S. E., \& Schlaggar, B. L. (2007). Development of distinct control networks through segregation and integration. Proceedings of the National Academy of Sciences of the United States of America, 104(33), 13507-13512. https://doi.org/10.1073/pnas.0705843104

Feldman, J. I., Cassidy, M., Liu, Y., Kirby, A. V., Wallace, M. T., \& Woynaroski, T. G. (2020). Relations between Sensory Responsiveness and Features of Autism in Children. Brain Sciences, 10(11), 775. https://doi.org/10.3390/brainsci10110775

Fiebelkorn, I. C., Foxe, J. J., McCourt, M. E., Dumas, K. N., \& Molholm, S. (2013). Atypical category processing and hemispheric asymmetries in high-functioning children with 
autism: Revealed through high-density EEG mapping. Cortex; a Journal Devoted to the Study of the Nervous System and Behavior, 49(5), 1259-1267.

https://doi.org/10.1016/j.cortex.2012.04.007

Floris, D. L., Barber, A. D., Nebel, M. B., Martinelli, M., Lai, M.-C., Crocetti, D., Baron-Cohen, S., Suckling, J., Pekar, J. J., \& Mostofsky, S. H. (2016). Atypical lateralization of motor circuit functional connectivity in children with autism is associated with motor deficits. Molecular Autism, 7(1), 35. https://doi.org/10.1186/s13229-016-0096-6

Floris, D. L., Wolfers, T., Zabihi, M., Holz, N. E., Zwiers, M. P., Charman, T., Tillmann, J., Ecker, C., Dell’Acqua, F., Banaschewski, T., Moessnang, C., Baron-Cohen, S., Holt, R., Durston, S., Loth, E., Murphy, D. G. M., Marquand, A., Buitelaar, J. K., Beckmann, C. F., \& EU-AIMS Longitudinal European Autism Project Group. (2021). Atypical Brain Asymmetry in Autism-A Candidate for Clinically Meaningful Stratification. Biological Psychiatry. Cognitive Neuroscience and Neuroimaging, 6(8), 802-812. https://doi.org/10.1016/j.bpsc.2020.08.008

Foss-Feig, J. H., Stavropoulos, K. K. M., McPartland, J. C., Wallace, M. T., Stone, W. L., \& Key, A. P. (2018). Electrophysiological response during auditory gap detection: Biomarker for sensory and communication alterations in autism spectrum disorder? Developmental Neuropsychology, 43(2), 109-122. https://doi.org/10.1080/87565641.2017.1365869

Foxe, J. J., Molholm, S., Del Bene, V. A., Frey, H.-P., Russo, N. N., Blanco, D., Saint-Amour, D., \& Ross, L. A. (2015). Severe Multisensory Speech Integration Deficits in HighFunctioning School-Aged Children with Autism Spectrum Disorder (ASD) and Their 
Resolution During Early Adolescence. Cerebral Cortex, 25(2), 298-312. https://doi.org/10.1093/cercor/bht213

Gage, N. M., Siegel, B., Callen, M., \& Roberts, T. P. L. (2003). Cortical sound processing in children with autism disorder: An MEG investigation. Neuroreport, 14(16), 2047-2051. https://doi.org/10.1097/00001756-200311140-00008

Gomes, H., Dunn, M., Ritter, W., Kurtzberg, D., Brattson, A., Kreuzer, J. A., \& Vaughan, H. G. (2001). Spatiotemporal maturation of the central and lateral N1 components to tones. Brain Research. Developmental Brain Research, 129(2), 147-155. https://doi.org/10.1016/s0165-3806(01)00196-1

Groen, M. A., Alku, P., \& Bishop, D. V. M. (2008). Lateralisation of auditory processing in Down syndrome: A study of T-complex peaks Ta and Tb. Biological Psychology, 79(2), 148-157. https://doi.org/10.1016/j.biopsycho.2008.04.003

Guthrie, D., \& Buchwald, J. S. (1991). Significance testing of difference potentials. Psychophysiology, 28(2), 240-244. https://doi.org/10.1111/j.1469-8986.1991.tb00417.x Habas, P. A., Scott, J. A., Roosta, A., Rajagopalan, V., Kim, K., Rousseau, F., Barkovich, A. J., Glenn, O. A., \& Studholme, C. (2012). Early Folding Patterns and Asymmetries of the Normal Human Brain Detected from in Utero MRI. Cerebral Cortex (New York, NY), 22(1), 13-25. https://doi.org/10.1093/cercor/bhr053

Hahamy, A., Behrmann, M., \& Malach, R. (2015). The idiosyncratic brain: Distortion of spontaneous connectivity patterns in autism spectrum disorder. Nature Neuroscience, 18(2), 302-309. https://doi.org/10.1038/nn.3919

Hornickel, J., Skoe, E., \& Kraus, N. (2009). Subcortical Laterality of Speech Encoding. Audiology \& Neuro-Otology, 14(3), 198-207. https://doi.org/10.1159/000188533 
Jansson-Verkasalo, E., Ceponiene, R., Kielinen, M., Suominen, K., Jäntti, V., Linna, S.-L., Moilanen, I., \& Näätänen, R. (2003). Deficient auditory processing in children with Asperger Syndrome, as indexed by event-related potentials. Neuroscience Letters, 338(3), 197-200. https://doi.org/10.1016/S0304-3940(02)01405-2

Jorgensen, A. R., Whitehouse, A. J. O., Fox, A. M., \& Maybery, M. T. (2021). Delayed cortical processing of auditory stimuli in children with autism spectrum disorder: A meta-analysis of electrophysiological studies. Brain and Cognition, 150, 105709. https://doi.org/10.1016/j.bandc.2021.105709

Knight, E. J., Oakes, L., Hyman, S. L., Freedman, E. G., \& Foxe, J. J. (2020). Individuals With Autism Have No Detectable Deficit in Neural Markers of Prediction Error When Presented With Auditory Rhythms of Varied Temporal Complexity. Autism Research, 13(12), 2058-2072. https://doi.org/10.1002/aur.2362

Koyama, S., Gunji, A., Yabe, H., Oiwa, S., Akahane-Yamada, R., Kakigi, R., \& Näätänen, R. (2000). Hemispheric lateralization in an analysis of speech sounds. Left hemisphere dominance replicated in Japanese subjects. Brain Research. Cognitive Brain Research, 10(1-2), 119-124. https://doi.org/10.1016/s0926-6410(00)00034-3

Lai, M.-C., Lombardo, M. V., \& Baron-Cohen, S. (2014). Autism. Lancet (London, England), 383(9920), 896-910. https://doi.org/10.1016/S0140-6736(13)61539-1

Lane, A. E., Young, R. L., Baker, A. E. Z., \& Angley, M. T. (2010). Sensory processing subtypes in autism: Association with adaptive behavior. Journal of Autism and Developmental Disorders, 40(1), 112-122. https://doi.org/10.1007/s10803-009-0840-2

Leavitt, V. M., Molholm, S., Gomez-Ramirez, M., \& Foxe, J. J. (2011). "What" and "where" in auditory sensory processing: A high-density electrical mapping study of distinct neural 
processes underlying sound object recognition and sound localization. Frontiers in Integrative Neuroscience, 5, 23. https://doi.org/10.3389/fnint.2011.00023

Leavitt, V. M., Molholm, S., Ritter, W., Shpaner, M., \& Foxe, J. J. (2007). Auditory processing in schizophrenia during the middle latency period (10-50 ms): High-density electrical mapping and source analysis reveal subcortical antecedents to early cortical deficits. Journal of Psychiatry \& Neuroscience : JPN, 32(5), 339-353.

Leung, R. C., Pang, E. W., Brian, J. A., \& Taylor, M. J. (2019). Happy and Angry Faces Elicit Atypical Neural Activation in Children With Autism Spectrum Disorder. Biological Psychiatry. Cognitive Neuroscience and Neuroimaging, 4(12), 1021-1030. https://doi.org/10.1016/j.bpsc.2019.03.013

Lewis, J. D., Evans, A. C., Pruett, J. R., Botteron, K. N., McKinstry, R. C., Zwaigenbaum, L., Estes, A. M., Collins, D. L., Kostopoulos, P., Gerig, G., Dager, S. R., Paterson, S., Schultz, R. T., Styner, M. A., Hazlett, H. C., Piven, J., \& Infant Brain Imaging Study Network. (2017). The Emergence of Network Inefficiencies in Infants With Autism Spectrum Disorder. Biological Psychiatry, 82(3), 176-185.

https://doi.org/10.1016/j.biopsych.2017.03.006

Lin, Q.-X., Wu, G.-H., Zhang, L., Wang, Z.-J., Pan, N., Xu, C.-J., Jing, J., \& Jin, Y. (2018). [Abnormal processing characteristics to basic emotional faces in the early phase in children with autism spectrum disorder]. Zhongguo Dang Dai Er Ke Za Zhi=Chinese Journal of Contemporary Pediatrics, 20(2), 134-139.

Loomes, R., Hull, L., \& Mandy, W. P. L. (2017). What Is the Male-to-Female Ratio in Autism Spectrum Disorder? A Systematic Review and Meta-Analysis. Journal of the American 
Academy of Child and Adolescent Psychiatry, 56(6), 466-474.

https://doi.org/10.1016/j.jaac.2017.03.013

Lord, C., Rutter, M., DiLavore, PC., Risi, S., Gotham, K., \& Bishop, SL. (2012). Autism

Diagnostic Observation Schedule, 2nd. Western Psychological Services.

Matsuzaki, J., Ku, M., Dipiero, M., Chiang, T., Saby, J., Blaskey, L., Kuschner, E. S., Kim, M.,

Berman, J. I., Bloy, L., Chen, Y., Dell, J., Liu, S., Brodkin, E. S., Embick, D., \& Roberts,

T. P. L. (2019). Delayed Auditory Evoked Responses in Autism Spectrum Disorder

across the Life Span. Developmental Neuroscience, 41(3-4), 223-233.

https://doi.org/10.1159/000504960

Matsuzaki, J., Kuschner, E. S., Blaskey, L., Bloy, L., Kim, M., Ku, M., Edgar, J. C., Embick, D., \& Roberts, T. P. L. (2019). Abnormal auditory mismatch fields are associated with communication impairment in both verbal and minimally verbal/nonverbal children who have autism spectrum disorder. Autism Research: Official Journal of the International Society for Autism Research, 12(8), 1225-1235. https://doi.org/10.1002/aur.2136

Molholm, S., Ritter, W., Murray, M. M., Javitt, D. C., Schroeder, C. E., \& Foxe, J. J. (2002). Multisensory auditory-visual interactions during early sensory processing in humans: A high-density electrical mapping study. Cognitive Brain Research, 14(1), 115-128. https://doi.org/10.1016/S0926-6410(02)00066-6

Näätänen, R., \& Picton, T. (1987). The N1 wave of the human electric and magnetic response to sound: A review and an analysis of the component structure. Psychophysiology, 24(4), 375-425. https://doi.org/10.1111/j.1469-8986.1987.tb00311.x

Narain, C., Scott, S. K., Wise, R. J. S., Rosen, S., Leff, A., Iversen, S. D., \& Matthews, P. M. (2003). Defining a left-lateralized response specific to intelligible speech using fMRI. 
Cerebral Cortex (New York, N.Y.: 1991), 13(12), 1362-1368.

https://doi.org/10.1093/cercor/bhg083

Nickl-Jockschat, T., Rottschy, C., Thommes, J., Schneider, F., Laird, A. R., Fox, P. T., \&

Eickhoff, S. B. (2015). Neural networks related to dysfunctional face processing in autism spectrum disorder. Brain Structure \& Function, 220(4), 2355-2371. https://doi.org/10.1007/s00429-014-0791-z

O’Donnell, S., Deitz, J., Kartin, D., Nalty, T., \& Dawson, G. (2012). Sensory processing, problem behavior, adaptive behavior, and cognition in preschool children with autism spectrum disorders. The American Journal of Occupational Therapy: Official Publication of the American Occupational Therapy Association, 66(5), 586-594. https://doi.org/10.5014/ajot.2012.004168

Orekhova, E., Butorina, A. V., Tsetlin, M. M., Novikova, S. I., Sokolov, P. A., Elam, M., \& Stroganova, T. A. (2013). Auditory magnetic response to clicks in children and adults: Its components, hemispheric lateralization and repetition suppression effect. Brain Topography, 26(3), 410-427. https://doi.org/10.1007/s10548-012-0262-x

Orekhova, E., Stroganova, T. A., Prokofiev, A. O., Nygren, G., Gillberg, C., \& Elam, M. (2009). The right hemisphere fails to respond to temporal novelty in autism: Evidence from an ERP study. Clinical Neurophysiology, 120(3), 520-529. https://doi.org/10.1016/j.clinph.2008.12.034

Orekhova, E. V., Stroganova, T. A., Prokofiev, A. O., Nygren, G., Gillberg, C., \& Elam, M. (2009). The right hemisphere fails to respond to temporal novelty in autism: Evidence from an ERP study. Clinical Neurophysiology, 120(3), 520-529. https://doi.org/10.1016/j.clinph.2008.12.034 
Pang, E. W., \& Taylor, M. J. (2000). Tracking the development of the N1 from age 3 to adulthood: An examination of speech and non-speech stimuli. Clinical Neurophysiology, 111(3), 388-397. https://doi.org/10.1016/S1388-2457(99)00259-X

Papousek, I., \& Schulter, G. (1999). EEG correlates of behavioural laterality: Right-handedness. Perceptual and Motor Skills, 89(2), 403-411. https://doi.org/10.2466/pms.1999.89.2.403

Parviainen, T., Helenius, P., \& Salmelin, R. (2019). Children show hemispheric differences in the basic auditory response properties. Human Brain Mapping, 40(9), 2699-2710. https://doi.org/10.1002/hbm.24553

Perry, A., Flanagan, H. E., Dunn Geier, J., \& Freeman, N. L. (2009). Brief report: The Vineland Adaptive Behavior Scales in young children with autism spectrum disorders at different cognitive levels. Journal of Autism and Developmental Disorders, 39(7), 1066-1078. https://doi.org/10.1007/s10803-009-0704-9

Ponton, C. W., Eggermont, J. J., Kwong, B., \& Don, M. (2000). Maturation of human central auditory system activity: Evidence from multi-channel evoked potentials. Clinical Neurophysiology, 111(2), 220-236. https://doi.org/10.1016/S1388-2457(99)00236-9

Qi, T., Schaadt, G., \& Friederici, A. D. (2019). Cortical thickness lateralization and its relation to language abilities in children. Developmental Cognitive Neuroscience, 39, 100704. https://doi.org/10.1016/j.dcn.2019.100704

Ramaswami, G., \& Geschwind, D. H. (2018). Genetics of autism spectrum disorder. Handbook of Clinical Neurology, 147, 321-329. https://doi.org/10.1016/B978-0-444-63233$3.00021-\mathrm{X}$ 
Ray-Subramanian, C. E., Huai, N., \& Weismer, S. E. (2011). Brief Report: Adaptive Behavior and Cognitive Skills for Toddlers on the Autism Spectrum. Journal of Autism and Developmental Disorders, 41(5), 679-684. https://doi.org/10.1007/s10803-010-1083-y

Ribolsi, M., Koch, G., Magni, V., Di Lorenzo, G., Rubino, I. A., Siracusano, A., \& Centonze, D. (2009). Abnormal brain lateralization and connectivity in schizophrenia. Reviews in the Neurosciences, 20(1), 61-70. https://doi.org/10.1515/revneuro.2009.20.1.61

Roberts, T. P. L., Matsuzaki, J., Blaskey, L., Bloy, L., Edgar, J. C., Kim, M., Ku, M., Kuschner, E. S., \& Embick, D. (2019). Delayed M50/M100 evoked response component latency in minimally verbal/nonverbal children who have autism spectrum disorder. Molecular Autism, 10(1), 34. https://doi.org/10.1186/s13229-019-0283-3

Rogers, S. J., Hepburn, S., \& Wehner, E. (2003). Parent reports of sensory symptoms in toddlers with autism and those with other developmental disorders. Journal of Autism and Developmental Disorders, 33(6), 631-642. https://doi.org/10.1023/b:jadd.0000006000.38991.a7

Rolison, M., Lacadie, C., Chawarska, K., Spann, M., \& Scheinost, D. (2021). Atypical Intrinsic Hemispheric Interaction Associated with Autism Spectrum Disorder Is Present within the First Year of Life. Cerebral Cortex (New York, N.Y.: 1991), bhab284. https://doi.org/10.1093/cercor/bhab284

Ross, L. A., Del Bene, V. A., Molholm, S., Frey, H.-P., \& Foxe, J. J. (2015). Sex differences in multisensory speech processing in both typically developing children and those on the autism spectrum. Frontiers in Neuroscience, 9. https://doi.org/10.3389/fnins.2015.00185 
Rysstad, A. L., \& Pedersen, A. V. (2016). Brief Report: Non-right-Handedness Within the Autism Spectrum Disorder. Journal of Autism and Developmental Disorders, 46(3), 1110-1117. https://doi.org/10.1007/s10803-015-2631-2

Schmidt, G. L., Rey, M. M., Oram Cardy, J. E., \& Roberts, T. P. L. (2009). Absence of M100 source asymmetry in autism associated with language functioning. Neuroreport, 20(11), 1037-1041. https://doi.org/10.1097/WNR.0b013e32832e0ca7

Schmitz, J., Packheiser, J., Birnkraut, T., Hinz, N.-A., Friedrich, P., Güntürkün, O., \& Ocklenburg, S. (2019). The neurophysiological correlates of handedness: Insights from the lateralized readiness potential. Behavioural Brain Research, 364, 114-122. https://doi.org/10.1016/j.bbr.2019.02.021

Shafer, V. L., Yu, Y. H., \& Wagner, M. (2015). Maturation of cortical auditory evoked potentials (CAEPs) to speech recorded from frontocentral and temporal sites: Three months to eight years of age. International Journal of Psychophysiology: Official Journal of the International Organization of Psychophysiology, 95(2), 77-93. https://doi.org/10.1016/j.ijpsycho.2014.08.1390

Sparrow, S., Cicchetti, D., \& Balla, D. (2005). Vineland Adaptive Behavior Scales, Second Edition. Pearson.

Stroganova, T. A., Kozunov, V. V., Posikera, I. N., Galuta, I. A., Gratchev, V. V., \& Orekhova, E. V. (2013). Abnormal Pre-Attentive Arousal in Young Children with Autism Spectrum Disorder Contributes to Their Atypical Auditory Behavior: An ERP Study. PLoS ONE, 8(7). https://doi.org/10.1371/journal.pone.0069100

Tonnquist-Uhlen, I., Ponton, C. W., Eggermont, J. J., Kwong, B., \& Don, M. (2003). Maturation of human central auditory system activity: The T-complex. Clinical Neurophysiology: 
Official Journal of the International Federation of Clinical Neurophysiology, 114(4), 685-701. https://doi.org/10.1016/s1388-2457(03)00005-1

Wechsler, D. (2011). Wechsler Abbreviated Scale of Intelligence-Second Edition. Pearson.

Wexler, B. E. (1980). Cerebral laterality and psychiatry: A review of the literature. The American Journal of Psychiatry, 137(3), 279-291. https://doi.org/10.1176/ajp.137.3.279

Williams, Z. J., Abdelmessih, P. G., Key, A. P., \& Woynaroski, T. G. (2020). Cortical Auditory Processing of Simple Stimuli Is Altered in Autism: A Meta-analysis of Auditory Evoked Responses. Biological Psychiatry: Cognitive Neuroscience and Neuroimaging, S2451902220302809. https://doi.org/10.1016/j.bpsc.2020.09.011

Wolpaw, J. R., \& Penry, J. K. (1975). A temporal component of the auditory evoked response. Electroencephalography and Clinical Neurophysiology, 39(6), 609-620. https://doi.org/10.1016/0013-4694(75)90073-5

Yamazaki, H., Easwar, V., Polonenko, M. J., Jiwani, S., Wong, D. D. E., Papsin, B. C., \& Gordon, K. A. (2018). Cortical hemispheric asymmetries are present at young ages and further develop into adolescence. Human Brain Mapping, 39(2), 941-954.

https://doi.org/10.1002/hbm.23893 